\title{
Prevalence of Depression among Medical Students of a Tertiary Care Teaching Hospital
}

Nikhil Shrestha, ${ }^{1}$ Neharika Shrestha, ${ }^{1}$ Smriti Khanal, ${ }^{2}$ Sujata Dahal, ${ }^{3}$ Roshan Lama, ${ }^{4}$ Prashant Simkhada ${ }^{5}$, Sudarshan N Pradhan ${ }^{6}$

'Oxford University Clinical Research Unit-Nepal, Lalitpur, Nepal, ${ }^{2}$ Tokha Chandeshwori Primary Health Center, Kathmandu, Nepal, ${ }^{3}$ Jibjibe Rural Hospital, Rasuwa, Nepal, ${ }^{4}$ Deurali Primary Health Center, Nuwakot, Nepal, ${ }^{5}$ Kanti Children's Hospital, Kathmandu, Nepal, ${ }^{6}$ Kathmandu Medical College, Sinamangal, Nepal.

Introduction: Depression is one of the major problems encountered by medical students. This may cause a negative effect on cognitive functioning and learning of students resulting in poor health care and service delivery in future. The presence of this major problem is necessary to be evaluated. Enough recent data regarding its prevalence is not available in our country. Thus, the main aim of this study is to find the prevalence of depression among medical students of a tertiary care teaching hospital.

Methods: This is a descriptive cross-sectional study was conducted among medical students of a tertiary care teaching hospital over a four-month period (July to October 2019) among undergraduate medical students. Ethical clearance was received from the Institutional Review Committee of the same tertiary teaching hospital. Random sampling technique was used to collect data to meet the calculated sample size. Data analysis was done in the Statistical Package for Social Sciences. Point estimate at $95 \%$ Confidence Interval was calculated along with frequency and proportion for binary data.

Results: The prevalence of depression among selected medical students of Kathmandu Medical College and Teaching Hospital is 59 (27.2\%) at 95\% Confidence Interval (21.28-33.12\%). Thirty (14\%) of the participants were mildly depressed, 21 (10\%) moderately depressed while $8(4 \%)$ were severely depressed according to Beck's Depression Index II.

Conclusions: Prevalence of depression among medical students is relatively significant as found in similar studies done in other centres. Thus appropriate programs and strategies should be implemented to avoid depression from causing a negative effect on cognitive functioning and learning of students and create a favorable environment for students to talk about their mental health issues.

Keywords: depression; medical students; prevalence.

\section{INTRODUCTION}

Medical students undergo many stressful situations. They have to deal with substantial academic, psychological as well as existential stressors during the duration of their undergraduate years. ${ }^{1}$ Studies have thus shown that medical students experience depression at a much higher rate than that of the general population, ${ }^{2,3}$ this has been an important issue in both the developed as well as developing nations.

Correspondence: Dr. Nikhil Shrestha, Oxford University Clinical Research Unit-Nepal, Lalitpur, Nepal. Email: shresthnik@gmail.com, Phone: +977-9843468391. 
The future doctors themselves are at risk of being victimized by depression. Over the course of their medical training, their mental health tends to deteriorate even more. ${ }^{4-9}$ This has lead to students opting for potentially detrimental coping mechanisms such as excessive use of alcohol, and the use of other substances. ${ }^{10}$ Depression has even been associated with suicidal ideation., $7,11,12$ Furthermore, in spite of their training medical students are unsuccessful to comprehend depression as a major illness, that necessitates proper medical treatment when it comes to caring for themselves. ${ }^{14}$

There has been limited study in the past, thus this study aims to find the prevalence of depression among medical students of Kathmandu Medical College Teaching Hospital, a tertiary care centre.

\section{METHODS}

A descriptive cross-sectional study was conducted in a tertiary hospital, KMCTH in Nepal. After taking the ethical clearance from the Institutional Review Committee of Kathmandu Medical College and Teaching Hospital, data was collected from 217 medical students of Kathmandu Medical College Teaching Hospital from July to October 2019. The sample size of this study was calculated using the formula,

Sample size was calculated using the formula;

$$
\begin{aligned}
n & =Z^{2} \times(p \times q) / e^{2} \\
& =1.96^{2} \times 0.5 \times(1-0.5) / 0.05^{2} \\
& =384
\end{aligned}
$$

where,

$\mathrm{n}=$ required sample size

$\mathrm{p}=$ prevalence of depression among medical students (50\%)

$\mathrm{q}=1-\mathrm{p}$

$\mathrm{e}=$ margin of error, $5 \%$

$\mathrm{Z}=1.96$ at $95 \% \mathrm{Cl}$

In the teaching hospital, population(N): 450

Adjusted Sample size $=\mathrm{n} / 1+\mathrm{n}-1 / \mathrm{N}$

$$
=207
$$

Therefore, the calculated sample size was 207. Adding the $5 \%$ non-response rate, the sample size that was taken is 217. Simple random sampling technique was applied. The list of the students in each batch was taken from the hospital's administration office, a consecutive number was given to the list. A random number table was utilized to select the sample. Medical students enrolled currently in the MBBS curriculum in the tertiary teaching hospital who gave consent were included in the study. Students in their internship year, those chronically absent or seriously ill at the time of the study were not included in the study. Randomly selected students were informed about the study and those willing to participate were given consent paper for signature. Then a self-administered validated Beck's Depression Inventory(BDI)-II questionnaire ${ }^{13}$ was distributed and collected from participants. Despite simple random sampling, the following bias could occur such as; Information bias, Reporting bias, Social desirability bias and Non-response bias.

Data collected was thoroughly checked for its completeness. Only those completed forms were included in the study. The data was then coded and double-entry done in IBM Statistical Package for Social Sciences version 23.0. The data was processed and analyzed by using simple descriptive statistics; in terms of percentage and frequency.

\section{RESULTS}

The period prevalence of depression among medical students in Kathmandu Medical College Teaching Hospital is 59 (27.20\%) 95\% Confidence Interval (21.28$33.12 \%)$. Thirty $(14 \%)$ of the participants were mildly depressed, 21 (10\%) moderately depressed while 8 (4\%) were severely depressed according to Beck's Depression Index II.

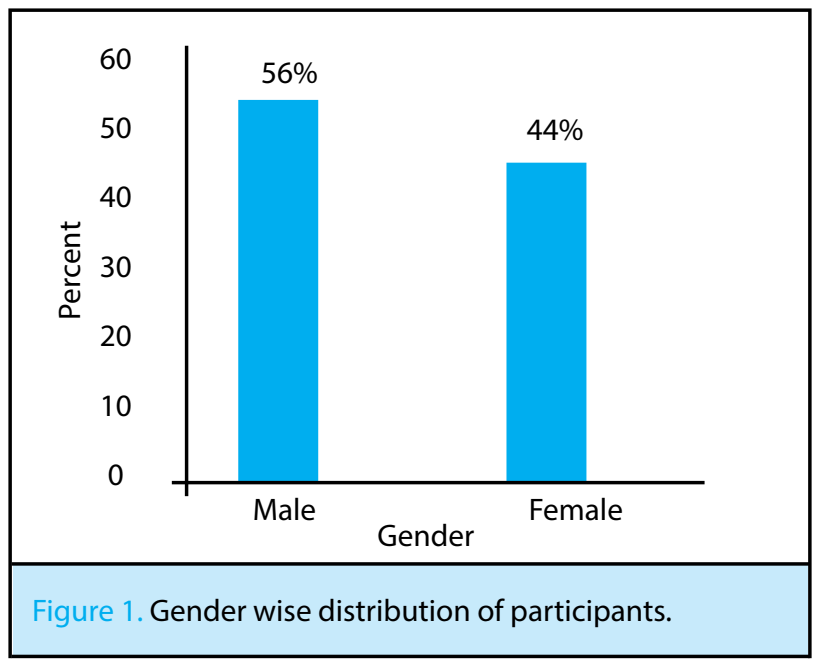

Among 217 participants, there were 121 (56\%) male and 96 (44\%) female; depression was more prevalentamong females than males (Figure 1). Fourteen (7\%) of female participants were mildly depressed, 9 (4\%) moderately depressed and 5 (2\%) severely depressed. Similarly, $16(7 \%)$ of male participants were mildly depressed, 12 (6\%) moderately depressed and 3 (1\%) severely depressed (Figure 2). 
Shrestha et al. Prevalence of Depression among Medical Students of a Tertiary Care Teaching Hospital

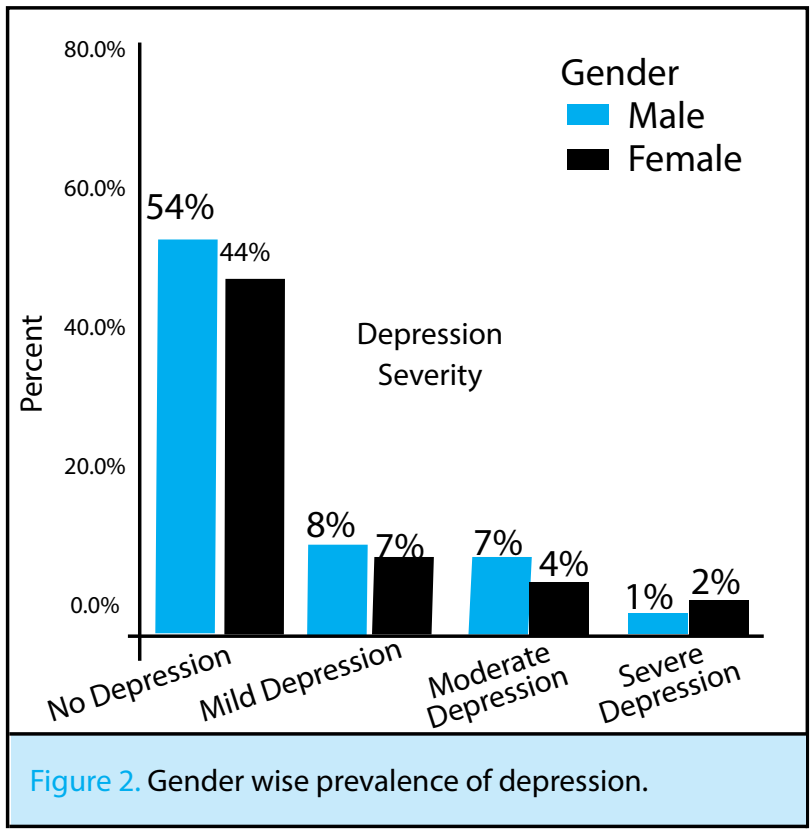

As medical students progressed to their clinical years, the prevalence of depression tends to increase. The prevalence of depression in 1st year, 2nd year, 3rd year and final year students was 14\%, 23\%, 30\%, and $14 \%$ respectively. This gave a prevalence of $34 \%$ in preclinical students in contrast to $44 \%$ in clinical students (Figure3).

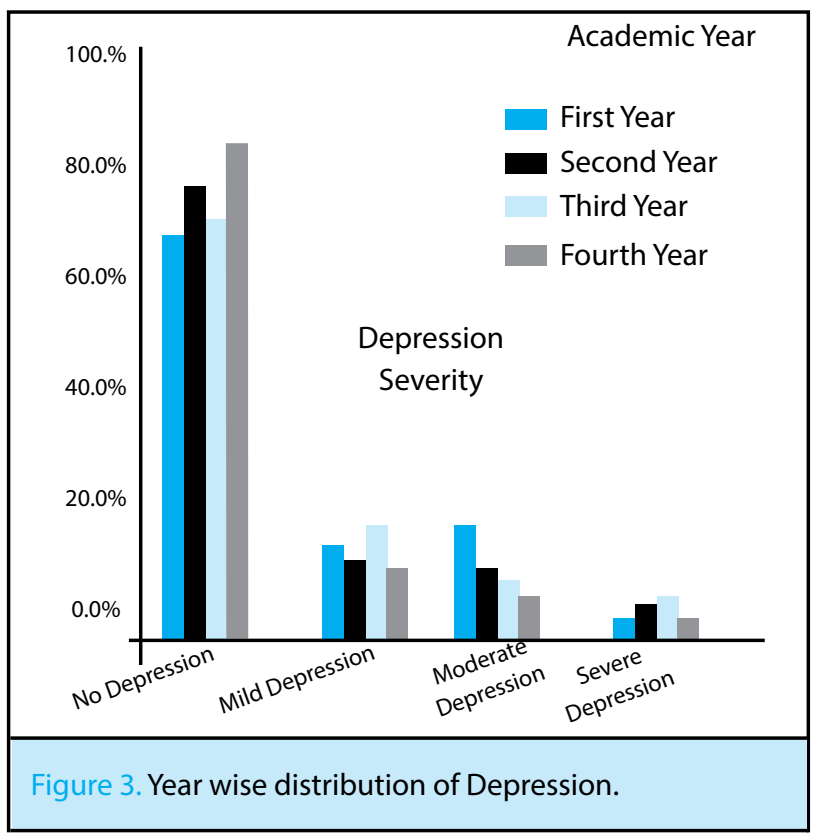

Regarding socio-demographics, almost all of the participants were within the age-group of 18-29 years. And none of the participants was married. Depression was more prevalent among females 28 (29\%) compared to males 31 (26\%).

Now moving to other factors, among the $27 \%$ of depressed participants, only 2 (1\%) had a family history of depression while 57 (26\%) of the depressed participant had no such family history. In this study, we also observed that more participants who were depressed used smoking or alcohol to cope with stress (46\%) compared to non-depressed participants (29\%).

Finally, we also observed that $23(11 \%)$ of the participant who felt like they were academically incompetent were depressed.

\section{DISCUSSION}

Due to substantial academic, psychological as well as existential stressors that the medical students should cope with, ${ }^{1}$ these subgroup populations are at higher risk of experiencing psychological and mental problems such as depression.

In our study, the prevalence of depression is found to be $27.20 \%$ which as compared to the previous study is lower. In the study done by Basnet $B$, et al. $^{15}$ the prevalence of depression was $29.7 \%$ with prevalence among female students being higher than those in males, $32 \%$ in females and $28 \%$ in males, which was similar to our study. This finding is also supported by a similar study done in Bristol by Knipe et al. which found a prevalence of $27 \%$ in females and $19 \%$ in males. ${ }^{16}$

A study done by Adhikari A, et al. found a similar prevalence of $29.2 \%$, in their study found that the prevalence of depression was higher among preclinical students (33\%) compared to clinical students $(22 \%),{ }^{17}$ which is in contrast to our study. However, a systematic review that was done by Rotenstein $L$ et al. at Harvard found no such difference. ${ }^{18}$ But a similar study done by Sreeramareddy $C$, et al. found that the prevalence rate was higher among clinical science students. ${ }^{19} 15 \%$, $18.9 \%$ and $24 \%$ in third, fourth and final year students respectively which was similar to our study which found that prevalence tended to increase as students started their clinical years (i.e. third year). Juggling time between postings, theory classes and trying to gain clinical experience can be the reason for overwhelming the students more at the beginning of clinical years, which could be the reason for the high prevalence in third-year students.

In comparison to students of other faculty, medical students have more stigma when it comes to mental health issues since their competency is also questioned, ${ }^{20}$ leading to more students having difficulty talking about their mental health problems. This in addition to academic stress and expectation from family might have the reason for higher percent depression (26\%) without any predisposing factor-like family history (1\%). 
The limitation of our study is that since the study was carried out only in a single teaching hospital, the findings of the study cannot be generalized to all student populations. During the time of the study, some student groups were in their exam period which could influence the responses resulting in an overestimation of the frequency of symptoms. This study being a cross-sectional study, our results only portray a point estimate, we are unable to determine if the proportion of students having sustained symptoms.

\section{CONCLUSIONS}

The prevalence of depression among medical students was found to be similar to the other similar studies done in other centres. The prevalence of depression among medical students is higher compared to the general population. This suggests the need of confidential and accessible mental healthcare and investment of resources into developing strategies and programs which reduce stress such as workshops on topics such as depression \& suicide, anxiety, burnout, and stress management decreasing the stigma related to it, along with trainings about counseling for mental health issues as a curriculum.

\section{ACKNOWLEDGEMENTS}

Our sincere hearty thanks and acknowledgement to all themedical students who participated in this study to make this study possible.

Conflict of Interest: None.

\section{REFERENCES}

1. Vaidya PM, Mulgaonkar KP. Prevalence of depression, anxiety and stress in undergraduate medical students and its correlation with their academic performance. Indian J of Occup Ther. 2007; 39:7-10. [Full Text]

2. Dahlin M, Joneborg N, Runeson B. Stress and depression among medical students: A cross-sectional study. Med Educ. 2005; 39: 594-604.[PubMed |DOI]

3. Zoccolillo M, Murphy GE, Wetzel RD. Depression among medical students. J Affect Disord. 1986; 11:91-96. [PubMed | DOI]

4. Carson AJ, Dias S, Johnston A, et al. Mental health in medical students: a case control study using the 60 item General Health Questionnaire. Scott Med J. 2000; 45(4):115-116. [PubMed | DOI]

5. Givens JL, Tjia J. Depressed medical students' use of mental health services and barriers to use. Acad Med.2002;77(9):918-921. [PubMed | DOI]

6. Rosal MC, Ockene IS, Ockene JK, Barrett SV, MaY, Hebert JR. A longitudinal study of students' depression at one medical school. Acad Med. 1997;72(6):542-546.[PubMed | DOI]

7. Dyrbye LN, Thomas MR, Shanafelt TD. Systematic review of depression, anxiety, and other indicators of psychological distress among US and Canadian medical students. Acad Med. 2006;81(4):354-373. [PubMed | DOI]

8. Goebert D, Thompson D, Takeshita J, et al. Depressive symptoms in medical students and residents: a multischool study. Acad Med. 2009;84(2):236-241.[PubMed | DOI]

9. Dyrbye LN, Thomas MR, Power DV, et al. Burnout and serious thoughts of dropping out of medical school: a multi-institutional study. Acad Med. 2010; 85(1):94-102. [ $\underline{\text { PubMed | DOI] }}$

10. Rosenthal JM,Okie S. White coat, mood indigo-depression in medical school. N Engl J Med. 2005;353(11):1085-1088. [․ㅡll text]
11. Dyrbye LN, Thomas MR, Massie FS, et al. Burnout and suicidal ideation among US medical students. Ann Intern Med. 2008;149(5):334-341. [PubMed | DOI]

12. Dahlin M, Joneborg N, Runeson B. Stress and depression among medical students: a cross-sectional study. Med Educ. 2005;39(6):594-604. [PubMed | DOI]

13. Storch EA, Roberti JW, Roth DA. Factor structure, concurrent validity, and internal consistency of the beck depression inventory-second edition in a sample of college students. Depression and anxiety. 2004;19(3):187-9. [PubMed | DOI]

14. Beck AT, Steer RA, Brown GK. 1996. Beck Depression Inventory-Second Edition manual. San Antonio, TX: The Psychological Corporation. [Full Text]

15. Basnet B, Jaiswal M, Adhikari B, Shyangwa PM. Depression among undergraduate medical students. Kathmandu University Medical Journal. 2012;10(3):56-9. [Full Text]

16. Knipe D, Maughan C, Gilbert J, Dymock D, Moran P, Gunnell D. Mental health in medical, dentistry and veterinary students: cross-sectional online survey. BJPsych Open. 2018 Nov;4(6):441-6. [PubMed | DOI]

17. Adhikari A, Dutta A, Sapkota S, Chapagain A, Aryal A, Pradhan A. Prevalence of poor mental health among medical students in Nepal: a cross-sectional study. BMC medical education. 2017 Dec;17(1):232. [PubMed | DOI]

18. Rotenstein LS, Ramos MA, Torre M, Segal JB, Peluso MJ, Guille C, Sen S, Mata DA. Prevalence of depression, depressive symptoms, and suicidal ideation among medical students: a systematic review and meta-analysis. Jama. 2016 Dec 6;316(21):2214-36. [PubMed | DOI]

19. Sreeramareddy CT, Shankar PR, Binu VS, Mukhopadhyay C, Ray B, Menezes RG. Psychological morbidity, sources of stress and coping strategies among undergraduate medical students of Nepal. BMC Medical education. 2007 Dec;7(1):26. [PubMed | DOI] 
20. Schwenk TL, Davis L, Wimsatt LA. Depression, stigma, and suicidal ideation in medical students. Jama. 2010 Sep 15;304(11):1181-90. [PubMed | DOI]

This work is licensed under a Creative Commons Attribution 4.0 International License. The images or other third party material in this article are included in the article's Creative Commons license, unless indicated otherwise in the credit line; if the material is not included under the Creative Commons license, users will need to obtain permission from the license holder to reproduce the material. To view a copy of this license, visit http://creativecommons.org/licenses/by/4.0/ 